\title{
Penetrating Heart Injuries and Common Difficulties Encountered During Emergency Surgery
}

\author{
Mahmut Tokur $^{\mathrm{a}}$, Mehmet Ergin ${ }^{\mathrm{b}, \mathrm{d}}$, Can Kurkcuoglu ${ }^{\mathrm{c}}$
}

\begin{abstract}
Background: Penetrating heart injuries are seldom but are highly lethal traumas. In-house cardiac surgery teams and adequate technical equipment are generally not found outside of major health institutions in Turkey. We evaluate the diagnosis and treatment of penetrating heart injuries, the difficulties encountered during surgical treatment of such conditions as well as problems faced by hospitals with limited cardiac surgery manpower and lacking adequate equipment to deal with such incidents.
\end{abstract}

Methods: The diagnosis of 'penetrating heart injury' between 1 January 2008 and 31 December 2009 was scanned through hospital data processing system. Eleven patients presenting to Kahramanmaras State Hospital were retrospectively evaluated.

Results: Three (26\%) of the patients presented with signs of hypovolemia, four $(37 \%)$ with progressive shock and four $(37 \%)$ with shallow respiration in addition to progressive shock. The etiology of the injuries were edged and sharp objects in $9(82 \%)$ cases, puncture from a fractured sternum and/or ribs in $2(18 \%)$ case. The total mortality was $63 \%$ in our case series.

Conclusions: Cardiac injuries are the types of trauma that require rapid surgical intervention. However, combination of a lack of specialized surgical teams and/or the time for rapid intervention at the initial health care facility reduces the possibility of surviving patient.

Manuscript accepted for publication June 7, 2012

${ }^{a}$ Kahramanmaras Sutcu Imam University, Medicine Faculty, Department of Thoracic Surgery, Kahramanmaras, Turkey

${ }^{b}$ Necmettin Erbakan University, Meram Medicine Faculty, Department of Emergency, Konya, Turkey

${ }^{c}$ Harran University, Medicine Faculty, Department of Thoracic Surgery, Sanliurfa, Turkey

${ }^{\mathrm{d}}$ Corresponding author: Mehmet Ergin, Necmettin Erbakan University

Meram Medicine Faculty Department of Emergency, Akyokus 42080

Meram, Konya, Turkey. Email: drmehmetergin@gmail.com

doi: $10.4021 / \mathrm{jcs} 86 \mathrm{w}$
Keywords: Emergency surgery; Heart injury; Penetrating trauma

\section{Introduction}

Penetrating heart injuries are caused by edged or sharp objects, firearms, and rarely by puncture from a fractured sternum or ribs. Cardiac injuries can range from damage to the pericardial sac to full-depth lacerations of the myocardium. Although penetrating heart injuries are less common compared to other types of penetrating injuries, they are more likely to be fatal [1]. Clinical findings in penetrating heart injuries range from a hemodynamically stable condition to cardiopulmonary arrest. The clinical presentation depends on the type of the injury, the time it takes to transport the victim to a trauma center, size of the myocardial laceration, amount of intravascular volume loss, presence of pericardial tamponade and the existence of accompanying organ injuries [2].

In this article, we evaluate the diagnosis and treatment of penetrating heart injuries, the difficulties encountered during surgical treatment of such conditions as well as problems faced by hospitals with limited cardiac surgery manpower and lacking adequate equipment to deal with such incidents in Turkey.

\section{Material and Method}

The diagnosis of 'penetrating heart injury' between 1 January 2008 and 31 December 2009 was scanned through hospital data processing system. The patients' files was evaluated and their age, gender, etiology and side of injury, clinical state, associated injuries, intraoperative findings, difficulties during surgery and results were recorded. The diagnostic and treatment approaches were compared with those given in the current literature.

\section{Results}

Eleven patients presenting to Kahramanmaras State Hospital 
Table 1. Analysis of Patients Based on Clinical Findings

\begin{tabular}{|c|c|c|c|c|c|}
\hline Case & Age & Gender & Etiology & Injury Side (Front/Back) & Clinical State At Application \\
\hline 1 & 24 & Male & Stabbed & Front /Left midclavicular line, 6th ICS* & $\begin{array}{l}\text { Hypotension and tachycardia/ } \\
\text { Stabile }\end{array}$ \\
\hline 2 & 19 & Male & Stabbed & Front /Xiphoid & $\begin{array}{l}\text { Deep shock and shallow } \\
\text { breathing }\end{array}$ \\
\hline 3 & 16 & Male & Stabbed & Front /Right parasternal region, 6th ICS & $\begin{array}{l}\text { Hypotension and tachycardia } \\
\text { / Stabile }\end{array}$ \\
\hline 4 & 16 & Male & Stabbed & Back /Left scapular inferior end & Deep shock \\
\hline 5 & 25 & Male & Stabbed & Back /Left posterior axiller line & $\begin{array}{l}\text { Deep shock and shallow } \\
\text { breathing }\end{array}$ \\
\hline 6 & 40 & Male & Sternal fracture & Front /Sternal corpus & Deep shock \\
\hline 7 & 53 & Male & Costal fracture & Front /Right parasternal region & Deep shock \\
\hline 8 & 65 & Female & Stabbed & Back/Left scapula lateral edge & Deep shock \\
\hline 9 & 14 & Male & Stabbed & Front /Left prasternal region, 5th ICS & $\begin{array}{l}\text { Hypotension and tachycardia/ } \\
\text { Stabile }\end{array}$ \\
\hline 10 & 25 & Male & Stabbed & Front /Left midclavicular line, 5th ICS & $\begin{array}{l}\text { Deep shock and shallow } \\
\text { breathing }\end{array}$ \\
\hline 11 & 30 & Male & Stabbed & Front /Left parasternal region, 4th ICS & $\begin{array}{l}\text { Deep shock and shallow } \\
\text { breathing }\end{array}$ \\
\hline
\end{tabular}

*ICS: Intercostal space

(Turkey) with penetrating heart injuries were encountered during the study period. The average age for the 10 male patients was 26.2, and the only female patient was 65 years old.

All the cases were initially evaluated in the emergency department (ED) and immediately after this evaluation, a chest surgeon was consulted for all patients. Nine patients underwent surgery with chest surgeon and for six of them, cardiac surgeons were also present in the surgical team.

Three $(26 \%)$ of the patients were presented with signs of hypovolemia (hypotension, tachycardia), four (37\%) with progressive shock (hypotension, tachycardia, cool extremities and loss of consciousness) and four (37\%) with shallow respiration in addition to progressive shock. These four patients were intubated in the ED and were taken straight into the operation room (OR) (Table 1). Four of the patients were brought into the ED with intravenous cannulation having been performed. Central venous catheterization was successfully performed in the ED for all patients. For the other seven patients, emergency blood count and computerized tomographic imaging were completed in the ED.
The etiology of the injuries revealed trauma were caused by edged and sharp objects in $9(82 \%)$ cases, by puncture from a fractured sternum and ribs in $1(9 \%)$ case and by puncture of a fractured rib in $1(9 \%)$ case. Pericardial rupture and pneumopericardium were seen in those cases caused by puncture from fractured bones following a blunt trauma. In nine cases caused by edged and sharp objects the object entry sites were noted as posterior side of left hemithorax in three patients, right parasternal region in one patient, xyphoid in one patient, anterior side of left hemithorax in four patients. The penetrating heart injuries in two patients from blunt trauma were caused by a puncture from fractured bones on the anterior chest wall (Table 1).

Left anterolateral thoracotomy was performed in four patients, left posterolateral thoracotomy was performed in three patients, right anterolateral thoracotomy in two patients, sternotomy was performed on one patient and one had a clamshell incision. In eight (73\%) of the patients, the left ventricle was damaged whereas right ventricle injury was seen in the remaining three $(27 \%)$ patients. Six $(55 \%)$ pa- 


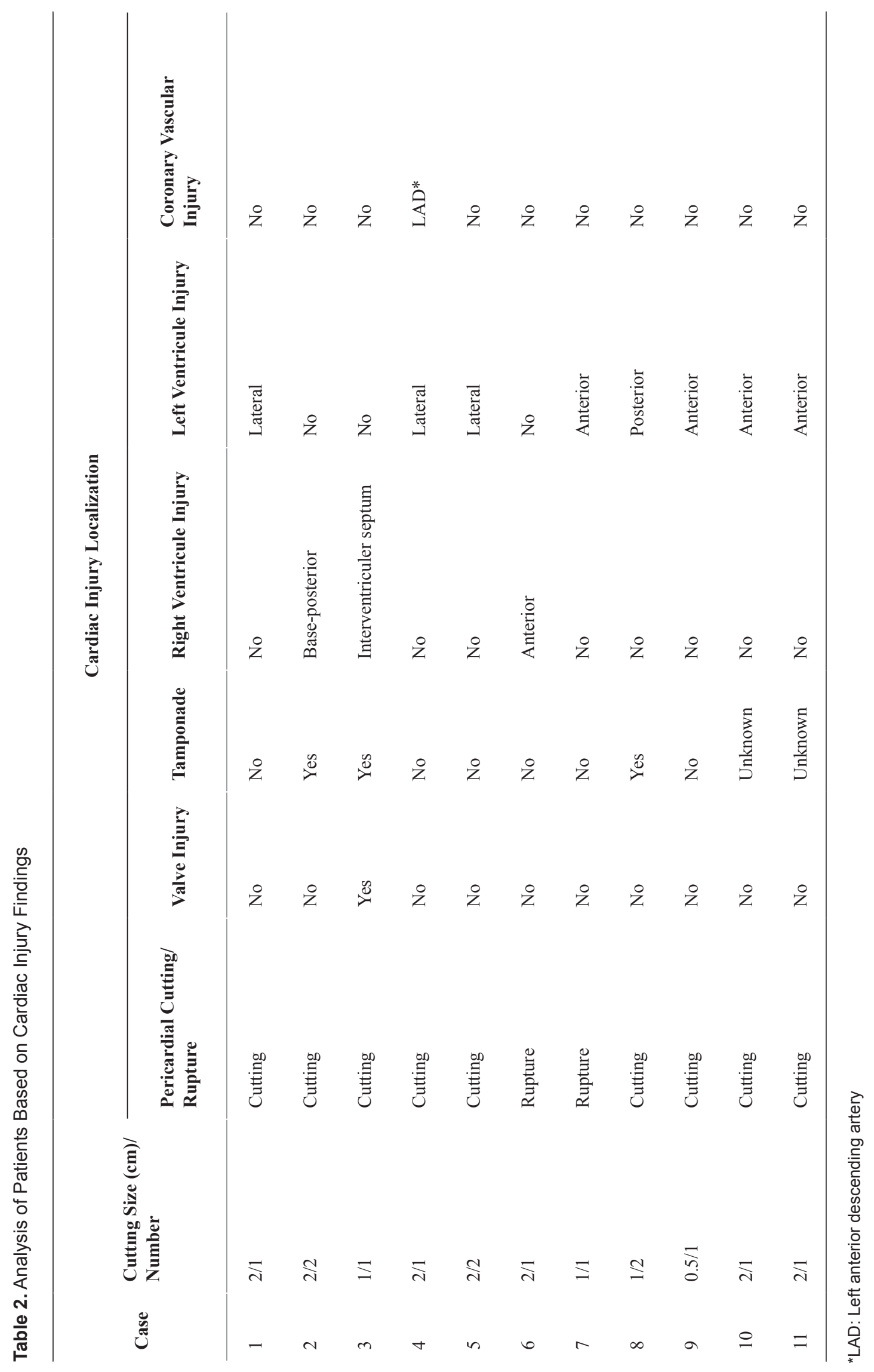




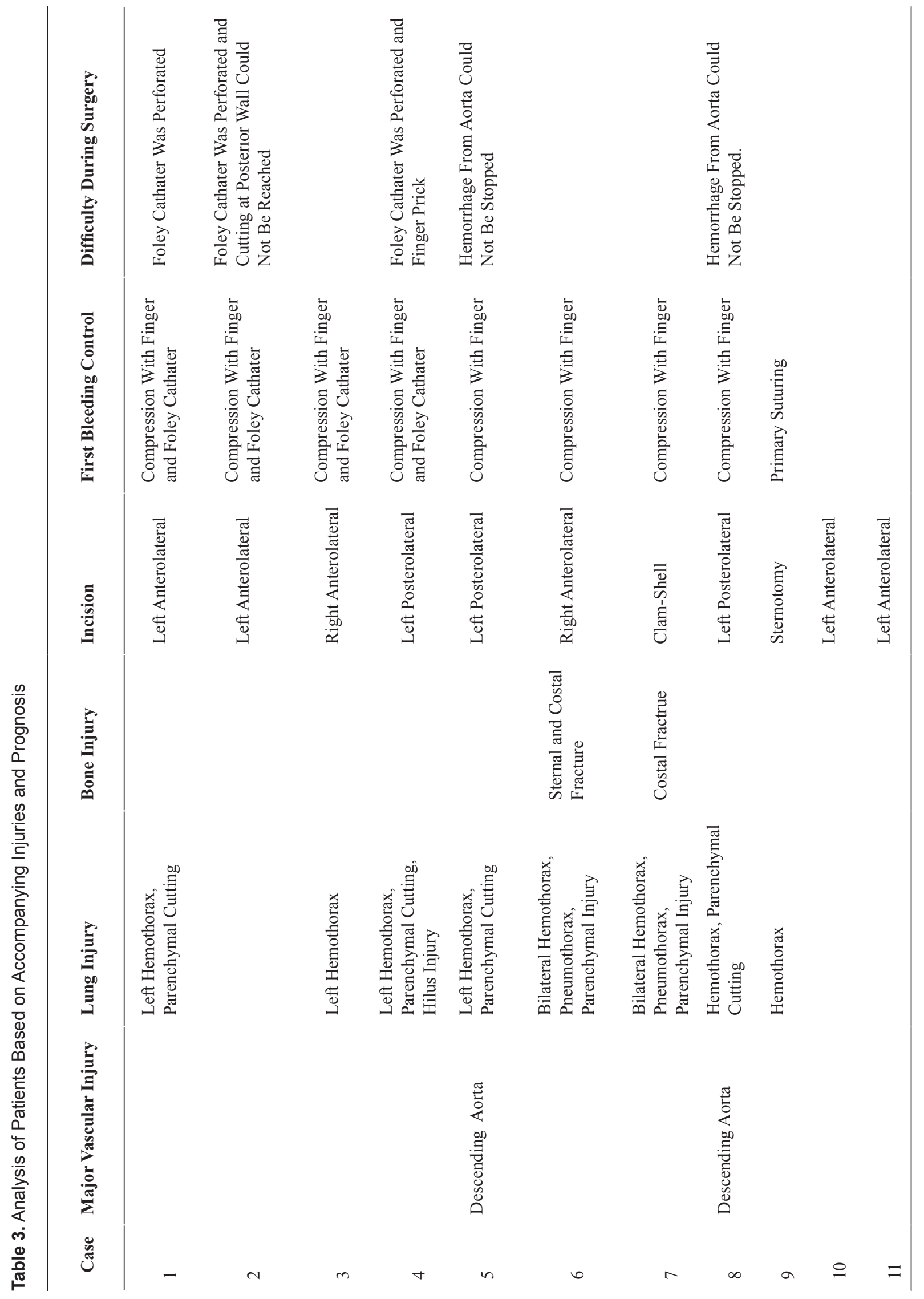


tients had hemothorax on the left side and two (18\%) had bilateral hemopneumothorax. Three patients had no hemothorax associated with their injuries. Other injuries by locations are as follows: six patients had injuries in the pulmonary parenchyma, one in the pulmonary hilus, two in the aorta, one in the coronary artery and one in the valves and one patient presented with injuries to anterior and posterior walls of the ventricle. The size of the lacerations in the heart ranged from $0.5 \mathrm{~cm}$ to $3 \mathrm{~cm}$ (Table 2 and 3 ).

Bleeding for the large lacerations was first controlled with finger pinch followed by a foley catheter. Lacerations were then repaired with $2 / 0-0-4 / 0$ propylene sutures. A pericardial patch was used in one case and pledgets in two others. Since the lacerations were repaired with full layer of sutures, the balloons of the Foley catheters were accidentally punctured number of times, which required the replacement with a new catheter during surgery. The patient who suffered a cut in the coronary artery could not be given a coronary by-pass surgery due to technical inadequacies and the artery had to be ligated. This patient died later due to perioperative myocardial infarction. Four (37\%) out of eleven patients were survived. Two patients died in ED, four died early in the post-surgery stage due to bleeding complications and one died 20 days after surgery due to pulmonary complications. The total mortality was $63 \%$ in our case series (Table 3 ).

\section{Discussion}

Of all trauma cases that require emergent surgical management $10.4 \%$ are chest trauma. About $1 \%$ of all chest traumas present with cardiac injuries [3]. About $75 \%$ of penetrating heart injuries results from edged and sharp objects in Turkey whereas $45-65 \%$ with firearm injuries in the USA, and 85 $95 \%$ with edged and sharp objects in South Africa and China [4-8].

The majority of the patients brought into the ED suffering from a penetrating heart injuries are hemodynamically unstable and have high risk of mortality, which is reported to vary between 3\% and 94\% depending on the type of injury sustained [4, 9-14]. The mortality rate varies based on the size of the injury, the overall condition of the patient and the presence of accompanying organ injuries. Most studies found that the mortality rates are higher in injuries caused by firearms [14-16]. None of our patients' injuries was caused by a firearm but the overall mortality rate was $63 \%$.

The frequency of the location of penetrating heart injuries are right ventricle, left ventricle, right atrium and left atrium. Even though injuries to the right ventricle are more common, the mortality is low compared to the other locations [17]. A generally accepted view is that the cardiac tamponade resulting from right ventricle injuries that only involves the heart chamber has positive impact on survivability. The exact mechanism for this is unknown; however, it is thought that the pressure caused by the thrombosed hematoma plays a role in limiting the bleeding [18-20]. In our patient group, the most commonly injured site was the left ventricle and three patients developed cardiac tamponade but only one of them survived.

Despite the advances made in pre-hospital emergency care, the majority of the patients with cardiac injuries die before reaching hospital [21]. Demetriades reported that only $20 \%$ survived to reach the hospital whereas Campbell et al found only $6 \%$ of their patients were alive upon arrival at hospital $[1,7]$. In Turkey, only $3.5 \%$ of the patients with penetrating heart injuries are found to survive until arrival at a hospital [22].

In certain cases, patient history, physical exam, injury location and clinical presentation of the patient are sufficient for diagnosis. Anatomically, injuries located in the frontal thorax, between the nipples, jugular notch of the sternum and upper abdomen are considered cardiac injuries unless proven otherwise [23].

Time should not be wasted on extensive diagnostic tests in patients with penetrating heart injuries. For the small number of hemodynamically stable patients echocardiography (ECHO)and computer tomography $(\mathrm{CT})$ can be performed. ECHO exams done prior to surgery could provide valuable insight about the presence of valvular or atrium/ ventricle injuries. In patients for whom pre-operative ECHO is not performed, transesophageal ECHO can be performed to evaluate the functions of the valves and intra-ventricular injuries [24]. We performed post-operative ECHO for one of our patients, but no additional treatment was required.

A median sternotomy can be performed in stable patients $[2,25]$. This technique provides clear and superior view of the heart, larger vessels and pulmonary hili. However, the technique may not be appropriate in reaching the lacerations on the posterior surface of the heart or the aorta and esophageus in posterior mediastinium injuries [25]. An anterolateral thoracotomy may be preferred in unstable patients and for patients in extremis. Compared to sternotomy, it can be performed more rapidly and can be extended into the opposing hemithorax by cutting through the sternum if needed $[2,8,25]$. Once a thoracotomy or sternotomy is performed, the pericardium should be opened and any tamponade should be released in order to make the heart visible [26]. Following that procedure, rapid control of bleeding and simultaneous fluid replacement to increase the cardiac output should be undertaken. Once essential stabilization has been performed, the repair of the laceration should be undertaken. Initial control of the bleeding can be accomplished by a finger or a foley catheter inserted in the laceration. The ultimate repair of the laceration following the initial bleeding control can be performed with a controlled manipulation while a finger is still inserted in the laceration or while a foley catheter is inserted and inflated in place. In this technique, while a finger is pressed against the lesion, 
a suture is placed with the other hand. The finger is moved upward after each suture is placed. The sutures should be placed through the entire thickness of the myocardium. For lacerations near the coronary arteries, sutures should be placed under the coronary arteries, without damaging the blood flow [27]. The final repair can also be performed without controlling the bleeding with a finger or foley catheter; however, this reduces the chance of survival for patients in shock.

There are number of practical difficulties when repairing a laceration in the heart. The suturing needle may pierce the finger or the glove while the finger is inserted into the laceration to control bleeding. Releasing the finger partially or completely to create room for suturing may result in massive bleeding in the injury site. A foley catheter may provide valuable time for bleeding control and fluid resuscitation. However, puncturing the catheter's balloon while suturing may result in massive bleeding and loss of volume. The time lost during the replacement of the catheter may be associated with increased mortality. The foley catheter may need to be over inflated for large sized lacerations and this result in reduction in the filling pressure and cardiac output [27]. These difficulties were encountered during the surgical procedures on almost all of our cases.

If coronary arteries lie near the lacerations on the myocardium, sutures can be placed horizontal to the arteries in order to maintain blood flow through them. Small coronary branches may be ligated. When both the heart and a coronary artery has been damaged with a single cut, placing the primary sutures over the coronary artery while focusing on the emergency bleeding control may result in intraoperative or postoperative myocardial infarction. This condition may necessitate a bypass during surgery $[26,28,29]$. A myocardial infarction developed in one of our patients for whom we were not able to provide coronary bypass after coronary artery ligation.

Cardiac injuries become more complicated and life threatening when they are accompanied by an injury to a coronary artery, great vessel, mammarian arteria thoracica interna artery or vein, valve, corda tendinia, or septum or when there are multiple lacerations on the myocardium. In these cases, morbidity or mortality may be seen following an emergent surgery for the primary repair of the heart laceration [28-30].

\section{Conclusion}

Since it is not always possible to transport the patient to a cardiac surgery facility where qualified cardiac surgeons are in attendance in Turkey, emergency physicians, general surgeons or chest surgeons are sometimes required to provide the interventions. When doctor's experience and the equipment and supplies are limited for such interventions, mortality rates increase unfortunately.

\section{References}

1. Campbell NC, Thomson SR, Muckart DJ, Meumann CM, Van Middelkoop I, Botha JB. Review of 1198 cases of penetrating cardiac trauma. Br J Surg. 1997;84(12):1737-1740.

2. Asensio JA, Petrone P, Karsidag T, Ramos-Kelly JR, Demiray S, Roldan G, Pak-Art R, et al. Penatrating cardiac injuries. Complex injuries and difficult challenges. Ulus Travma Acil Cerrahi Derg. 2003;9(1):1-16.

3. Arikan S, Yucel AF, Kocakusak A, et al. Penetran kardiyak travmali hastalarin retrospektif analizi. Ulus Travma Derg 2003; 9:124-8.

4. Demirkiran SM, Tekin GA. Cardiac penetration wounds: three years Adana Numune Hospital experience. Ulus Travma Acil Cerrahi Derg. 2003;9(1):30-33.

5. Golbasi I, Turkay C, Sahin N, Erdogan A, Gulmez H, Erbasan O, Bayezid O. Heart wounds. Ulus Travma Derg. 2001;7(3):167-171.

6. Yanar H, Baspinar, Taviloglu K, et al. Penetran kalp yaralanmalari. Cagdas Cerrahi Dergisi 2005; 19:77-80.

7. Demetriades D, van der Veen BW. Penetrating injuries of the heart: experience over two years in South Africa. J Trauma. 1983;23(12):1034-1041.

8. Gao JM, Gao YH, Wei GB, Liu GL, Tian XY, Hu P, Li $\mathrm{CH}$. Penetrating cardiac wounds: principles for surgical management. World J Surg. 2004;28(10):1025-1029.

9. Mandal AK, Sanusi M. Penetrating chest wounds: 24 years experience. World J Surg. 2001;25(9):1145-1149.

10. Alanezi K, Milencoff GS, Baillie FG, Lamy A, Urschel JD. Outcome of major cardiac injuries at a Canadian trauma center. BMC Surg. 2002;2:4.

11. Altun G, Altun A, Yilmaz A. Hemopericardium-related fatalities: a 10-year medicolegal autopsy experience. Cardiology. 2005;104(3):133-137.

12. Ivatury RR, Nallathambi MN, Roberge RJ, Rohman M, Stahl W. Penetrating thoracic injuries: in-field stabilization vs. prompt transport. J Trauma. 1987;27(9):10661073.

13. Johnson SB, Nielsen JL, Sako EY, Calhoon JH, Trinkle JK, Miller OL. Penetrating intrapericardial wounds: clinical experience with a surgical protocol. Ann Thorac Surg. 1995;60(1):117-120; discussion 120-111.

14. Henderson VJ, Smith RS, Fry WR, Morabito D, Peskin GW, Barkan H, Organ CH, Jr. Cardiac injuries: analysis of an unselected series of 251 cases. J Trauma. 1994;36(3):341-348.

15. Tyburski JG, Astra L, Wilson RF, Dente C, Steffes C. Factors affecting prognosis with penetrating wounds of the heart. J Trauma. 2000;48(4):587-590; discussion 590-581.

16. Thourani VH, Feliciano DV, Cooper WA, Brady KM, Adams AB, Rozycki GS, Symbas PN. Penetrating cardiac trauma at an urban trauma center: a 22 -year perspec- 
tive. Am Surg. 1999;65(9):811-816; discussion 817-818.

17. Cikrikcioglu M, Yagdi T, Posacioglu H, et al. Penetran kalp yaralanmalari. Ulus Travma Derg 2000; 6:189-92.

18. Asensio JA, Berne JD, Demetriades D, Chan L, Murray J, Falabella A, Gomez H, et al. One hundred five penetrating cardiac injuries: a 2-year prospective evaluation. J Trauma. 1998;44(6):1073-1082.

19. Ulku R, Eren S, Balci A, Ozcelik C, Eren MN. Penetrating heart wounds. An analysis of 29 cases. Ulus Travma Derg. 2001;7(3):172-175.

20. Moreno C, Moore EE, Majure JA, Hopeman AR. Pericardial tamponade: a critical determinant for survival following penetrating cardiac wounds. J Trauma. 1986;26(9):821-825.

21. Mittal V, McAleese P, Young S, Cohen M. Penetrating cardiac injuries. Am Surg. 1999;65(5):444-448.

22. Fedakar R, Turkmen N, Durak D, Gundogmus UN. Fatal traumatic heart wounds: review of 160 autopsy cases. Isr Med Assoc J. 2005;7(8):498-501.

23. Cakir O, Eren S, Balci AE, et al. Penetran kalp yaralanmalari. Turk Gogus Kalp Damar Cer Derg 1999; 7:112-6.

24. Meyer DM, Jessen ME, Grayburn PA. Use of echo- cardiography to detect occult cardiac injury after penetrating thoracic trauma: a prospective study. J Trauma. 1995;39(5):902-907; discussion 907-909.

25. Ivatury RR. The injured heart. In: Mattox KL, Feliciano DV, Moore EE, editors. Trauma. 4th ed. New York: McGraw-Hill; 2000. p. 545-58.

26. Symbas PN. Cardiothoracic trauma. Curr Probl Surg. 1991;28(11):741-797.

27. Chang WY, Hsu JY, Chang YP, et al. The Successful Management of a Penetrating Cardiac Injury in a Regional Hospital: A Case Report J Emerg Crit Care Med. Vol. 162 19, No. 4, 2008.

28. Crawford FA. Penetrating Cardiac Injuries. In: Textbook of Surgery: The Biological Basis of Modern Surgical Practice, 14th ed. Sabiston DC, editor. Philadelphia: Saunders, 1991.

29. Choo MH, Chia BL, Chia FK, Johan A. Penetrating cardiac injury evaluated by two-dimensional echocardiography. Am Heart J. 1984;108(2):417-420.

30. Wall MJ, Jr., Mattox KL, Chen CD, Baldwin JC. Acute management of complex cardiac injuries. J Trauma. 1997;42(5):905-912. 